\section{SAT0220 EVALUATION OF LIVE ZOSTER VACCINE IN A SUBSET OF PATIENTS WITH RHEUMATOID ARTHRITIS TREATED WITH TOFACITINIB WITH OR WITHOUT METHOTREXATE, AND ADALIMUMAB WITH METHOTREXATE: RESULTS FROM A PHASE 3B/4 RANDOMISED TRIAL}

L. H. Calabrese ${ }^{1}$, C. Abud-Mendoza ${ }^{2}$, S. Lindsey ${ }^{3}$, S.-H. Lee ${ }^{4}$, L. Takiya ${ }^{5}$, N. likuni ${ }^{6}$, K. Soma ${ }^{7}$, Z. Luo ${ }^{8}$, R. Fleischmann ${ }^{9}{ }^{1}$ Cleveland Clinic Foundation, Cleveland, OH, United States, ${ }^{2}$ Hospital Central, San Luis Potosí, Mexico, ${ }^{3}$ Ochsner Medical Center, Baton Rouge, LA, United States, ${ }^{4}$ Konkuk University School of Medicine, Seoul, Korea, Republic Of, ${ }^{5}$ Pfizer Inc, Collegeville, PA, ${ }^{6}$ Pfizer Inc, New York, NY, ${ }^{7}$ Pfizer Inc, Groton, CT, United States, ${ }^{8}$ Pfizer Inc, Shanghai, China, ${ }^{9}$ Metroplex Clinical Research Center and University of Texas Southwestern Medical Center, Dallas, TX, United States

Background: Tofacitinib is an oral Janus kinase inhibitor for the treatment of rheumatoid arthritis (RA). Patients (pts) with RA are at increased risk for herpes zoster $(\mathrm{HZ})$ and this risk is further increased with tofacitinib treatment. ${ }^{1}$

Objectives: To evaluate the effect of live zoster vaccination (LZV) on $\mathrm{HZ}$ rates in a subset of methotrexate inadequate responder (MTX-IR) pts with RA who received tofacitinib with or without MTX, or adalimumab (ADA) with MTX in the ORAL Strategy randomised controlled trial (RCT). ${ }^{2}$

Methods: ORAL Strategy (NCT02187055) was a Phase 3b/4, 1-year, tripledummy active-comparator-controlled RCT. Pts were randomised 1:1:1 to receive tofacitinib $5 \mathrm{mg}$ twice daily (BID; tofa mono), tofacitinib $5 \mathrm{mg}$ BID+MTX (tofa + MTX), or subcutaneous ADA $40 \mathrm{mg}$ every other week + MTX (ADA+MTX); target MTX dose was 15-25 mg/week. In countries where LZV was available, pts aged $\geq 50$ years received LZV at the investigator's discretion, 28 days before the first dose of study drug. $\mathrm{HZ}$ incidence rates (IR; pts with events per 100 pt-years) and $95 \%$ confidence intervals $(\mathrm{Cl})$ were calculated for each treatment arm and for vaccinated vs non-vaccinated pts.

Table 1. IRs and $95 \% \mathrm{Cls}$ of $\mathrm{HZ}$ (serious and non-serious), and demographic characteristics among patients vaccinated and not vaccinated against $\mathrm{HZ}$ in the ORAL Strategy RCT

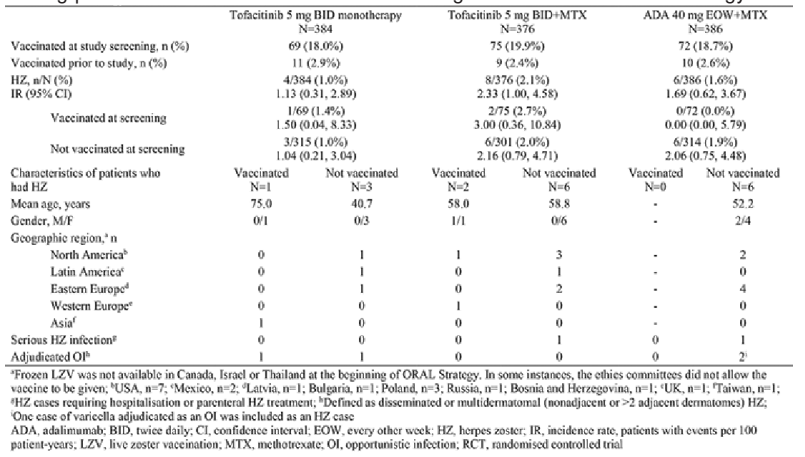

Results: Of 1146 pts who received study drug (mean age: 50.1 years), 216 received LZV (proportion of pts who received LZV by treatment group: tofa mono: 18.0\%; tofa+MTX: 19.9\%; ADA+MTX: 18.7\%) 28 days before randomisation in this RCT; 30 pts self-reported prior vaccination (Table). No pts had zoster-like lesions within 42 days of vaccination; 1 pt had vaccination site erythema. In the overall study population, HZ IR was similar between tofa mono and ADA+MTX and numerically higher (overlapping $\mathrm{Cl}$ ) with tofa+MTX. IRs were generally similar for pts who received LZV (18.8\% of pts were vaccinated) vs those who did not (81.2\%) (Table). Overall, 18/1146 pts had HZ. Among vaccinated pts, 3 (1.4\%) had HZ: no events were serious and $1(0.5 \%)$ event was multidermatomal (tofa mono). Among pts not vaccinated, $15(1.6 \%)$ had $\mathrm{HZ}$ : there were $2(0.2 \%)$ serious $H Z$ events (tofa+MTX: $n=1$; ADA+MTX: $n=1), 2(0.2 \%)$ multidermatomal events (tofa mono: $n=1 ; A D A+M T X: n=1)$ and $1(0.1 \%)$ disseminated event (ADA+MTX). Conclusions: In MTX-IR pts with RA, LZV was well-tolerated. HZ IR was numerically similar between tofa mono and ADA+MTX and higher with tofa+MTX. $\mathrm{HZ}$ rates were generally similar in pts who received LZV vs those not vaccinated. LZV has shown efficacy in prevention of $\mathrm{HZ}$ in $51 \%$ (pts $\geq 60$ years old) and $70 \%$ (50-59 years old) of immunocompetent adults. ${ }^{3}$ Efficacy of LZV could not be fully evaluated as a minority ( $<20 \%$ ) of pts received LZV and not all geographic regions studied in other tofacitinib studies were represented.

\section{REFERENCES:}

[1] Winthrop, et al. Arthritis Rheumatol 2014;66:2675-84.

[2] Fleischmann, et al. Lancet 2017;390:457-68.

[3] Hales, et al. MMWR Morb Mortal Wkly Rep 2014;63:729-31.
Acknowledgements: Study sponsored by Pfizer Inc. Medical writing support was provided by D Binks of CMC and funded by Pfizer Inc.

Disclosure of Interest: L. Calabrese Grant/research support from: Celgene, Crescendo, Consultant for: Celgene, Crescendo, Speakers bureau: Celgene, Crescendo, C. Abud-Mendoza Consultant for: Bristol-Myers Squibb, Pfizer Inc, Roche, Speakers bureau: Bristol-Myers Squibb, Merck-Serono, Pfizer Inc, Roche, UCB, S. Lindsey Speakers bureau: Pfizer Inc, S.-H. Lee: None declared, L. Takiya Shareholder of: Pfizer Inc, Employee of: Pfizer Inc, N. likuni Shareholder of: Pfizer Inc, Employee of: Pfizer Inc, K. Soma Shareholder of: Pfizer Inc, Employee of: Pfizer Inc, Z. Luo Shareholder of: Pfizer Inc, Employee of: Pfizer Inc, R. Fleischmann Grant/research support from: AbbVie, Amgen, AstraZeneca, Bristol-Myers Squibb, Celltrion, Genentech, GSK, Janssen, Lilly, Novartis, Pfizer Inc, SanofiAventis, and UCB, Consultant for: AbbVie, Amgen, AstraZeneca, Bristol-Myers Squibb, Celltrion, Genentech, GSK, Janssen, Lilly, Novartis, Pfizer Inc, SanofiAventis, and UCB

DOI: 10.1136/annrheumdis-2018-eular.1469

\section{SAT0221 EFFECT OF TOFACITINIB ON REDUCING PAIN IN PATIENTS WITH RHEUMATOID ARTHRITIS, PSORIATIC ARTHRITIS AND ANKYLOSING SPONDYLITIS}

A. Ogdie ${ }^{1}$, K. de Vlam², I. B. McInnes ${ }^{3}$, P. J. Mease ${ }^{4}$, P. Baer ${ }^{5}$, T. Lukic ${ }^{6}$, K. Kwok ${ }^{6}$ C. Wang ${ }^{7}$, M.-A. Hsu ${ }^{7}$, A. Maniccia ${ }^{6}{ }^{1}$ Perelman School of Medicine at the University of Pennsylvania, Philadelphia, PA, United States, ${ }^{2}$ UZ Leuven, Leuven, Belgium, ${ }^{3}$ University of Glasgow, Glasgow, United Kingdom, ${ }^{4}$ Swedish Medical Center and University of Washington, Seattle, WA, United States, ${ }^{5}$ Baer Weinberg MPC, Scarborough, ON, Canada, ${ }^{6}$ Pfizer Inc, New York, NY, ${ }^{7}$ Pfizer Inc, Groton, $C T$, United States

Background: Tofacitinib is an oral Janus kinase inhibitor for the treatment of rheumatoid arthritis (RA) and psoriatic arthritis (PsA), which has also been evaluated in other inflammatory rheumatic diseases (IRD) including ankylosing spondylitis (AS). Pain contributes substantial morbidity in patients (pts) with IRD and directly impacts treatment adherence, assessment of disease improvement and health-related quality of life.

Objectives: To evaluate the effectiveness of tofacitinib in reducing pain in randomised controlled clinical trials in pts with RA, PsA and AS.

Methods: Five pt populations treated with tofacitinib $5 \mathrm{mg}$ twice daily (BID), 10 $\mathrm{mg}$ BID or placebo (PBO) were evaluated: [1] conventional synthetic diseasemodifying antirheumatic drug (cSDMARD)-inadequate response (IR) RA pts pooled from ORAL Scan (NCT00847613), ORAL Sync (NCT00856544) and ORAL Standard (NCT00853385), [2] tumour necrosis factor inhibitor (TNFi)-IR RA pts from ORAL Step (NCT00960440), [3] csDMARD-IR PsA pts from OPAL Broaden (NCT01877668), [4] TNFi-IR PsA pts from OPAL Beyond (NCT01882439) and [5] AS pts from a Phase 2 study (NCT01786668). Pain outcomes evaluated from baseline to Month (M)6 (Week [W]12 in the AS population) included Pt's Assessment of Arthritis Pain (PAAP) (RA and PsA populations only), Short-Form Health Survey (SF)-36v2 Q7 (bodily pain in the past week), SF36v2 Bodily Pain Domain (BP), EuroQol Five Dimensions Questionnaire Pain/Dis comfort Domain (EQ-5D PD; all populations) and Bath Ankylosing Spondylitis Disease Activity Index (BASDAI) Q2 (level of AS neck, back or hip pain) and Q3 (other pain) score (PsA and AS populations only; PsA pts had presence of spondylitis at screening and baseline BASDAI total score $>0$ in the full analysis set [FAS]). Data were analysed descriptively.

Results: The csDMARD-IR RA, TNFi-IR RA, csDMARD-IR PsA, TNFi-IR PsA and AS populations comprised a total of 2066, 399, 316, 394 and 155 pts in the FAS, respectively. In each RA or PsA csDMARD-IR and TNFi-IR population treated with tofacitinib, mean PAAP at baseline $(5 \mathrm{mg} \mathrm{BID}$, range $55.7-65.7 \mathrm{~mm}$; $10 \mathrm{mg}$ BID, 54.4-60.1 mm) decreased as early as W2 (1st post-baseline assessment; $45.8-49.8 \mathrm{~mm} ; 38.9-44.8 \mathrm{~mm}$ ) and continued to decrease through M6 (30.9-34.4 mm; 28.2-36.7 mm); decreases were numerically greater vs $\mathrm{PBO}$ and the magnitude of change in RA and PsA populations was similar (Table). Improvements in SF-36v2 Q7 (Table), SF-36v2 BP (Table) and EQ-5D PD were observed in all 4 RA and PSA csDMARD-IR and TNFi-IR populations, and in BASDAI Q2 and Q3 in the csDMARD-IR PsA and TNFi-IR PsA populations. In the AS population, improvements from baseline in mean SF-36v2 Q7 (Table), SF-36v2 BP (Table), EQ-5D PD and BASDAI Q2 were reported at W12 and were numerically greater vs $\mathrm{PBO}$. 